\title{
Study and investigation on the Mechanism and Design of Smart Quick Stop Device on Scrutiny of Chip Formation of Al 7075
}

\author{
Samad Dadvandipour \\ associate professor, University of Miskolc \\ Institue of Information Science, Department of Applied Information Engineering \\ 3515 Miskolc, Miskolc-Egyetemváros, e-mail: aitsamad@uni-miskolc.hu
}

\begin{abstract}
On the application of information engineering, especially in industry, we usually need to have a study on those problems which are essential for the producers of goods of any kind. Even though the precision machining is very competitive in the world market and industry, and the quick stop device has few competitors; however, still, many manufacturing factories use conventional types of equipment and machining methods. Furthermore, the decision-makers of these factories are not able to go on parallel with the new and intelligent technologies for the solution of the tribulations during the processes of machine cells due to different conditions and problems. To our understanding, the chip formation has become a critical problem in machining processes of metal cutting, at these types of manufacturing companies for its sophisticated pattern structure. The present paper aims at reviewing some samples of quick stop devices and discussing their functionalities. The discussion and reviewing yielded a design of a new and straightforward smart, quick stop device. The new device operates without making use of any unpredictable charges and requiring any particular tool or machining condition for turning operations. The prototype smart, quick stop device resulted in well and adequate functionality for research work and was used to study the chip formation. Moreover, it is different from conventional ones as it is mounted on the workpiece rather than the tool, which gives advantages to its functionality. The study has a further application for smart detection of chip shape formation in an intelligent industrial environment. Still, the current paper is only devoted to the development and design of a quick stop device in turning processes.
\end{abstract}

Keywords: Study, Investigation, Mechanism, Chip formation, quick stop devices

\section{Introduction}

Chip formation is one of the most critical and complex processes in machining operations. As it is not only affected by machining conditions (cutting speed, feed rate, depth of cut) but also depends on cutting tool parameters (tool material, tool geometry, type of coating) too. The environmental conditions, machine tool stiffness, tool holding, and clamping method have effects in the processes. Ordinarily and generally, machining of metals is characterized by a typically high level of elastoplastic deformation of the work material, and this results in a tremendous level of strain rate and high temperatures, which increases the difficulty and complexity of chip formation analysis and its study. If we want to simplify the chip formation mechanisms, there will be a need for comments and explanations and apply theoretical analyses too. Also, a quick stop device helps to prove and support theories and models beforehand. For example, in the case of simulation of chip formation employing a finite element, it is necessary to validate the model, through quick stop devices performance. Also, 
these devices let us the measurement of chip parameters such as chip curvature, shear plane angle. In the case of materials that produce a built-up edge, quick stop devices may be used as an appropriate tool to study built-up edge geometry. In such mechanisms, the machining process is stopped quickly by moving the tool and work material apart at a higher speed more than the cutting speed. The chip is left attached to the workpiece (sometimes with a scrap of the attached cutting piece) [5],[1]. The quick stop devices have been in use since the 1920s, as shown by the works of Rosenheim and Sturmey [6],[2]. Most quick stop devices are based on some form of shear-pin design, which resists the cutting forces during a normal machining operation. At the moment of separation, the shear pin is broken by a sudden impact, thus allowing the tool and workpiece to separate, and the machining operation is interrupted. Methods employed to break the shear pin are based on different design strategies. T.Vorm developed a quick stop device, using a drop hammer with a mass of approximately $75 \mathrm{~kg}$ to break the shear pin that had been dimensioned so as to withstand the cutting force [3].



Figure 1. An example of a quick stop device before and after having operations [8]

Since the stopping process must take a short interval of time, it must be noted to minimize this 'separation time' to get a frozen chip representative for the machining process under investigation. He also proposed an analytical model for the determination of the separation time in the frozen-chip technique. Other researchers used some external power sources to impact the tool, breaking the shear pin and accelerating the tool away from the workpiece. Some quick stop devices employed an explosive charge, which either acts directly on a tool holding block or a bolt against a tool block. Nevertheless, the acceleration will be non-uniform, the initial value being less than values reached later in the process. Ellis et al. [4] employed a commercial explosive motor in their designed quick stop device. When the gun is shot, the bolt is accelerated to impact the tool block and breaks the notched shear pin. The root diameter of the pins was determined so that the force required to break the pin was greater than the maximum tangential cutting force but less than the sum of the tangential cutting and the energy provided by the gun bolt. Philip [8] designed an explosive quick stop device that is characterized by a limited number of parts, reduced mass of the projectile, a variable combustion chamber, and a simplified ignition system. He claimed that the time of complete tool retraction and the dynamic stability during cutting are the criteria for evaluating the operating efficiency of the quick stop device.Yusuf Ozcatalbas, 2003 used a quick stop device for the study of chip formation and built-up edge formation in the machining of $\mathrm{Al} 4 \mathrm{C} 3-\mathrm{Al}$ composite and the morphologies of chip roots were determined, and chip forming was investigated by optical microscopy and SEM [9]. Lin and et al. used an explosive charge quick stop device to study the chip formation mechanism during machining of SiC- particle reinforced aluminum metal matrix composite [7]. 
Dahunsi and Awopetu used an indirect impact quick- stop for the analysis of chip root of $\alpha$-titanium alloy BT5 in a semi-finish turning operation [10]. The quick-stop mechanism, with the cutting tool held in place in the tool holder, is mounted in the position of the tool post just like the dynamometers. Figure 1 presents the indirect impact quick-stop device in the front elevation, before and after actuation. In their method, a shear pin that was notched and made out of cast iron was broken when the free end lever is struck, causing the cutting tool holding end to drop out of contact with the workpiece. We may see this figure with its reference in most of the papers related to the quick stop device, because of its design and material properties. Nabhani [11] used a quick stop device that employes a pivoted tool holder supported by a shear pin in the study of aerospace titanium alloys.
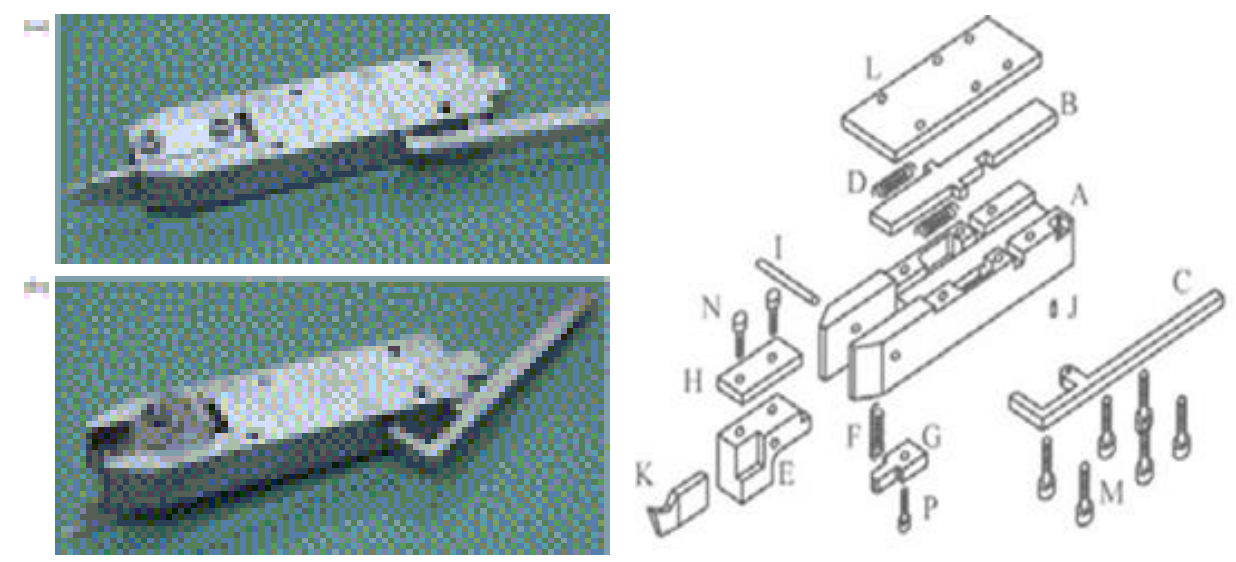

Figure 2. A quick stop device designed by Chern (2a) [12], prototype simulated model using re-engineering $(2 b)$

After achieving the desired cutting conditions, a capacitive bolt gun is used. It breaks the shear pin, thereby accelerates the tool in its holder to be away from the workpiece. In figure2. 2(a), we can see a Chern type view of a quick stop device [12]. In his device, a cutting tool clamped in a tool post with the help of a plate and screws. It is made of 8 parts together with two pins, three springs, and nine screws and operated by a trigger lever. Our research group manufactured several prototypes of his device at Tractor Manufacturing Company (I. T. M. Co.), one of them was shown in figure 2(b) where it was produced using the re-engineering method. We supposed that the re-enginnerd quick stop device could perform efficiently. It did not meet the study of chip formation of hard materials, with a deeper depth of cut, because the device damage was inevitable. Applying HSS made tool, needed standard Inserts. Furthermore, the pressure of tool post screws causes the deformation of the plate (L) and produces a problem in sliding motion of part (B). The specification of the re-engineered quick stop device is shown in figure $2.2 \mathrm{~b}$.

\section{The Prototype Quick Stop Device}

Concerning the study, as mentioned earlier review, the new device should follow some conditions to be a cost-effective and useful one as follows:

- time duration when the tool-workpiece needs for the disjointing process, and it is necessary to be as short as possible.

- the changes due to the geometry and mechanical properties of the chip should be limited to a minimum. 
- as the turbulences and vibration alter the machining conditions, then the device should have the least number of moving parts since it causes the instability of the process.

- the device to be standard cutting without complex modification as well as safe and easy to be used and adaptable to commercial machine tools too.

- the setup and resetting time to be performed in a very short time.

- the device to be reliably manufactured easily and cheaply.

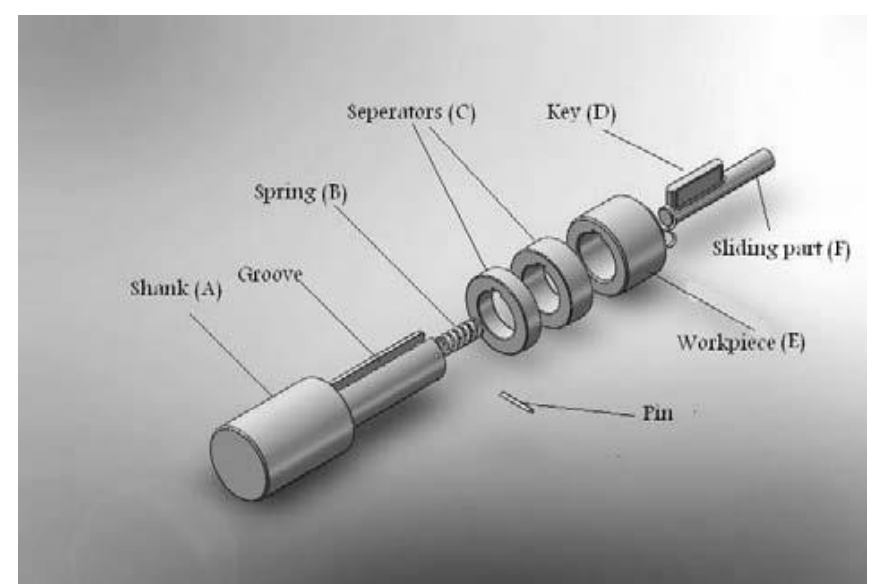

Figure 3. Exploded view of the new quick stop device

The designing of a new quick stop device considers all the cases in order not to cause the conventional type quick stop device's problems like involving any shear pins, hammers, or unpredictable charges. The prototype quick stop device features have the following specifications: -the total number of components is restricted (limited). - the selection of cutting tools is not limited, and standard cutting tools can be used. - the components are of simple geometry and applicable for turning and drilling processes. - the device is adaptable and flexible to the size changes and is applied for small and big workpieces. -setting and resetting time of the device between operations is very short, and due to experience less than a few minutes (2-3 minutes) - it is characterized as a mechanical device using principles of mechanical engineering Figure 3.

\section{Set up and Explanation of Smart Prototype Quick Stop Device}

For the good performance of the prototype new quick stop device, it is necessary to provide only a hole and a keyway in it. It is performed with the same size of a hole and keyway of the workpiece. After having the workpiece in hand, the quick stop device is mounted on the lathe chuck by the shank of the device (A), and then by using a dial indicator, the quick stop device is balanced and ran out errors were eliminated. Then the workpiece was mounted to the device, lathe center was engaged with sliding part $(\mathrm{F})$, and the turning operation started. During turning, the lathe center was moved toward the chuck. By this action, the key is released from the engagement of the workpiece, and the shank is rotated by the chuck and let the workpiece stay without rotation with an attached chip. The diameter of the device may be changed, so it allows us the mounting of small and big workpieces. 


\section{Experimental Tests}

The quick stop device was used for the study of chip formation in the turning of Al 7075 alloy, which of high strength as it matured (developed) by heat treatment. It also has very good properties at low temperatures. Due to its high strength, Al 7075 is used for highly stressed structural parts. Applications include aircraft fittings, gears, and shafts, fuse parts, meter shafts and gears, missile parts, regulating valve parts, worm gears, keys, and various other commercial aircraft, aerospace and defense equipment. Rod and bar product forms can be machined on multi-spindle and CNC machining equipment. The chemical compositions of this alloy are as Table1. A set of performed tests applied for the study of chip formation in the turning process of Al7075. Figure 6 shows the setup process of a quick stop device.
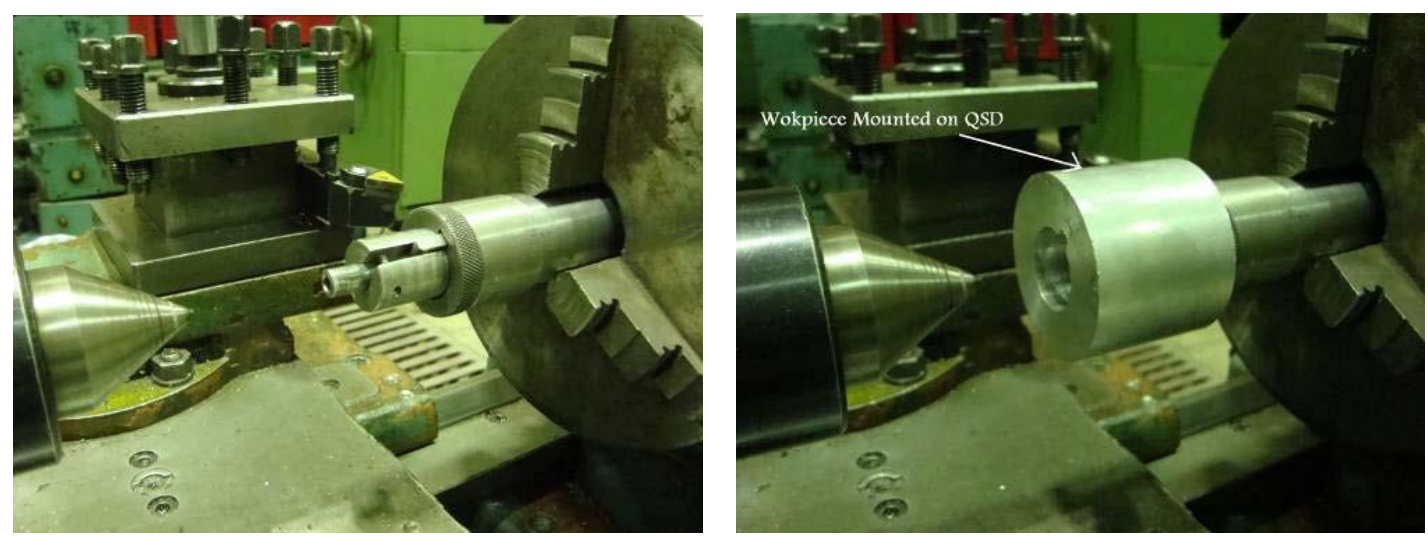

Figure 4. Set up of the quick stop device

Table 1. Chemical composition of Al 7075

\begin{tabular}{|l|l|l|l|l|l|l|l|l|}
\hline Aluminum & Chromium & copper & Iron & Magnesium & Manganese & Silicon & Titanium & Zinc \\
\hline Balance & $0.18-0.28$ & $1.2-2$ & $0.5 \max$ & $2.1-2.9$ & $0.3 \max$ & $0.4 \max$ & $0.2 \max$ & $6.1-5.1$ \\
\hline
\end{tabular}

Table 2. Experimental conditions used in this paper

\begin{tabular}{|c|c|c|c|c|c|}
\hline Experiment No. & $\begin{array}{c}\text { Spindle Speed } \\
(\mathbf{r p m})\end{array}$ & $\begin{array}{c}\text { Cutting Speed } \\
(\mathbf{m} / \mathbf{m i n})\end{array}$ & $\begin{array}{c}\text { Feed Rate } \\
(\mathbf{m m} / \mathbf{r e v})\end{array}$ & $\begin{array}{c}\text { Depth of Cut } \\
(\mathbf{m m})\end{array}$ & $\begin{array}{c}\text { BUE Height } \\
(\mathbf{m m})\end{array}$ \\
\hline 1 & 710 & 101.49 & 0.08 & 2 & NO \\
\hline 2 & 500 & 71.47 & 0.08 & 2 & 1.43 \\
\hline 3 & 355 & 55.76 & 0.28 & 2 & 1.21 \\
\hline 4 & 355 & 45.72 & 0.08 & 2 & 1.48 \\
\hline 5 & 355 & 66.91 & 0.12 & 1 & 1.34 \\
\hline 6 & 355 & 66.91 & 0.16 & 1 & 1.25 \\
\hline 7 & 250 & 42.41 & 0.12 & 1.5 & NO \\
\hline 8 & 125 & 19.63 & 0.28 & 1.5 & NO \\
\hline
\end{tabular}



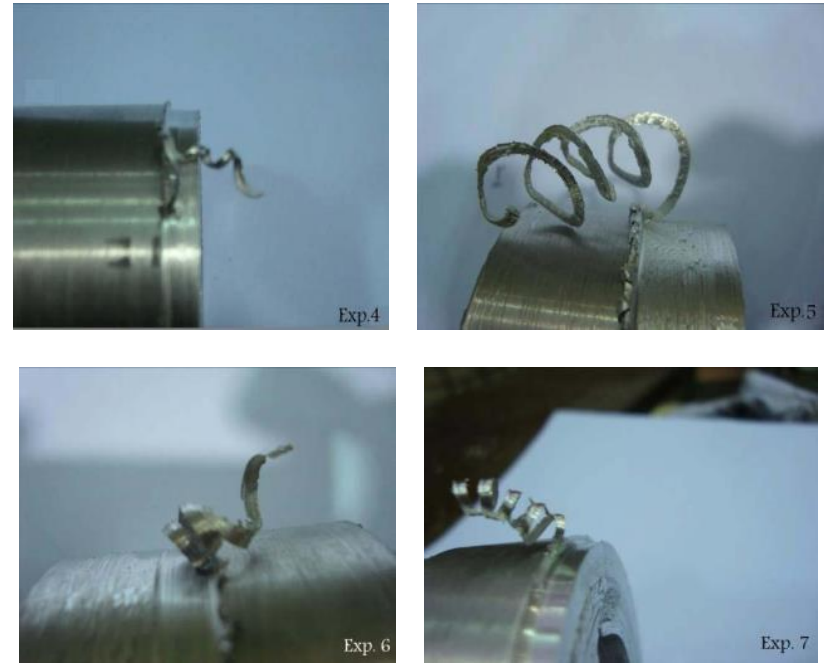

Figure 5. The produced chip attached to the workpiece for the experiment

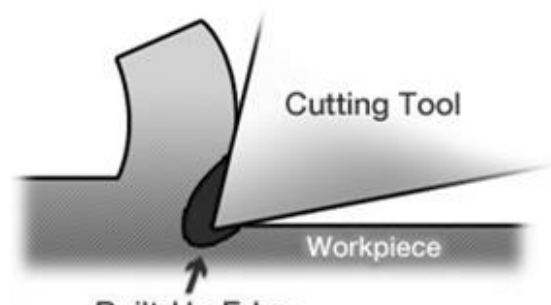

Built-Up Edge

Figure 6. Formation of built-up edge (BUE) due to heat and friction between tool and workpiece

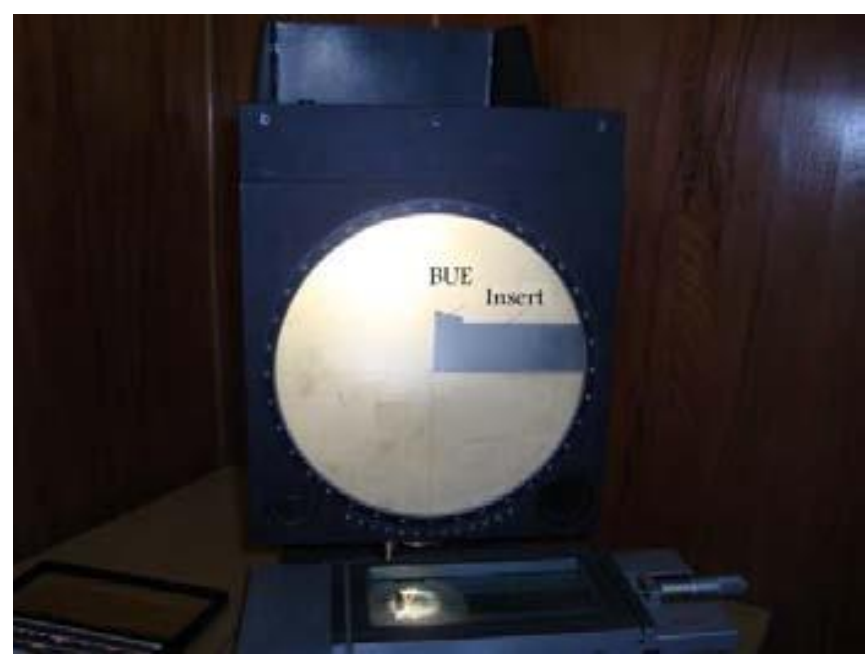

Figure 7. Built-up edge (BUE) on the tool rack angle measured by a profile projector 


\section{CONCLUSIONS}

The total number of components is quite limited, and there is no restriction on the selection of cutting standard tools. Also, the geometry of all parts is simple for producing. The developed quick stop device can operate at high cutting speeds. The study of chip formation during turning of Al 7075 showed that in low cutting speeds up to $43 \mathrm{~m} / \mathrm{min}$, there is no BUE, and between 43 to about 80 $\mathrm{m} / \mathrm{min}$, the BUE was produced and in high cutting speeds no BUE was observed. The collected chip samples showed that the variation of machining parameters influence the chip shape.

\section{References}

[1] Masuzawa T.: State of the art of micromachining. CIRP Annals - Manufacturing Technology, 2000, 49:473488. https://doi.org/10.1016/S0007-8506(07)63451-9

[2] Byrne G., Dornfeld D.: Denkena B.: Advancing cutting technology. CIRP Annals Manufacturing Technology 2003, 52:483-507. https://doi.org/10.1016/S0007-8506(07)60200-5

[3] Vorm,T.: Development of a quick- stop device and an analysis of the frozen-chip technique, International Journal of Machine Tool Design and Research 1963, 9:321-339.

[4] Ellis, J., Kirk, R., Barrow, G.: The development of a quick-stop device for metal cutting research. International Journal of Machine Tool Design and Research 1969,9:321-339. https://doi.org/10.1016/0020-7357(69)90007-9

[5] Childs, T., Maekawa, K., Obikawa, T., Yamane, Y.: Metal Machining Theory and Applications, 2000.

[6] Rosenhaim, W., Sturney, A.C.: 1925 Report on flow and rupture of metals during cutting.Proceedings of the Institution of Mechanical Engineers (U.K) 2008, 114:141-174. https://doi.org/10.1243/PIME_PROC_1925_108_015_02

[7] Lin, J.T., Bhattacharyya, D., Ferguson, W.G.: Chip formation in the machining of sic-particlereinforced aluminium-matrix composites. Composites Science and Technology 58, 285-291, 1998. https://doi.org/10.1016/S0266-3538(97)00126-7

[8] Philip, P.K.: Study of the performance characteristics of an explosive quick-stop device for freezing cutting action. International Journal of Machine Tool Design and Research 1971, 11:133-144. https://doi.org/10.1016/0020-7357(71)90022-9

[9] Ozcatalbas, Y.: Chip and built-up edge formation in the machining of in situ Al4C3-Al composite. Materials and Design 2003,24:215-221. https://doi.org/10.1016/S02613069(02)00146-2

[10] Dahunsi, O.A., Awopetu, O.O.: -The use of an indirect impact quick-stop mechanism during the turning of $\alpha$-titanium BT5 alloy. Int. J. Machining and Machinability of Materials 2008, 3:12. https://doi.org/10.1504/IJMMM.2008.017626

[11] Nabhani, F.: Machining of aerospace titanium alloys. Robotics and Computer Integrated Manufacturing 2001, 17:106. https://doi.org/10.1016/S0736-5845(00)00042-9

[12] Chern, G.L. Development of a new and simple quick stop device for the study on chip formation. International Journal of Machine Tools \& Manufacture 2006, 45:853-859. 